\title{
Psycholinguistic Background of Training English Discussion Skills in Students of Philology Departments
}

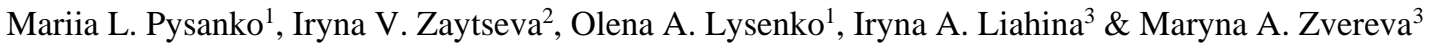 \\ ${ }^{1}$ Department of the English Language and Translation, Faculty of Oriental Studies, Kyiv National Linguistic \\ University, Kyiv, Ukraine \\ ${ }^{2}$ Department of Foreign Philology and Translation, Kyiv National University of Trade and Economics, Kyiv, \\ Ukraine \\ ${ }^{3}$ Department of Romance Philology and Comparative-typological Linguistics, Institute of Philology, Borys \\ Grinchenko Kyiv University, Kyiv, Ukraine \\ Correspondence: Iryna V. Zaytseva, Kyiv National University of Trade and Economics, 19, Kyoto str., Kyiv, 02156, \\ Ukraine.
}

Received: June 10, 2020

Accepted: August 3, 2020

Online Published: August 10, 2020

doi:10.5430/ijhe.v9n7p289

URL: https://doi.org/10.5430/ijhe.v9n7p289

\begin{abstract}
The efficiency of training of students of Philology Departments depends on the level of their communicative skills, that is, their abilities to participate in spontaneous discussion. This arises the issue of training these skills in the English majors. The research intends to determine and analyse the psychological background of Training English discussion skills in students of Philology Departments, to substantiate the difficulties that may arise at the initial stage. The authors analysed theoretical findings and practitioners' experience on discussion skills training. The survey determined motives of Ukrainian university students for participation in discussions and the obstacles that may arise. The article identifies the attitude of students of Philology Departments towards the problems and issues to be discussed, and the most urgent, interesting and challenging topics for the discussion. The discussion is characterised by the role of communication, motivation, cotextuality, spontaneity, emotional colouring, and the topic of discussion. Age peculiarities of the first-year students have an impact on the learning process and may complicate it. As a social group, students are characterised by confidence in their future profession, a stable attitude towards the chosen profession, while the level of the students' perceptions of their profession directly correlates with the level of their attitude towards the studies. The results of the survey prove the students' high motivation, their readiness to communicate and participate in discussions organised by the teachers in class. The topics and problems suggested included personally, professionally, socially and socio-culturally related issues that can be discussed. The most part of the students chose 'youth problems' (57\%) as the most urgent. The survey gives the opportunity to determine four groups of difficulties/obstacles that most of the students come across when participating in English discussion: psycholinguistic (caused by the nature of the dialogical speech); linguistic (caused by the language); psychological (caused by students); methodological (caused by teaching methods). The findings can be taken into account while conducting the further research on the problem of developing curricula, syllabus, teaching materials and manuals for teaching English as the major in the universities.
\end{abstract}

Keywords: psychological background, students of Philology Departments, discussion, difficulties, the English language

\section{Introduction}

The current rapid pace of life, international integration and new technologies urge learning foreign languages in the modern society. A modern philologist should be a professional who can adapt to new conditions, solve problems of theoretical and practical significance, is capable of constructive professional activity.

At the current stage of the development of our society, the problem of fluency in a foreign language becomes especially relevant in many spheres, including the educational one. So, the educational paradigm sets out quite high requirements for students of Philology Departments regarding the level of their foreign language proficiency at the initial stage. The curriculum provides for their ability to hold a discussion, comment on information received, draw conclusions, and find a compromise. 
The difficulties of Training English discussion skills in students of Philology Departments are characterised by the perception and interpretation of a large volume of information, the need to plan further steps/actions and keep them in mind, to correct and supplement it according to the way of holding the discussion, follow the partner's steps/actions, and observe time limits (Toptyhina, 2004).

According to the problem research method (a method which helps to create problem situations in the process of learning for students to solve), we define the concept of "discussion" as a form of an active exchange of opinions concerning controversy situations and finding ways to solve them (Lawtie, 2016; Thornbury, 2009). Such an interpretation of the concept of "discussion" allows identifying its aspects:

- The role of communication;

- $\quad$ Motivation, because there should be a motive for communication (Renandya, 2014; Zimniaia, 2001);

- A situation, because it is the situation of communication that provides a significant proportion of the information, not the text of the statement (Chernysh, 2013). These may include some past events known only to interlocutors, their experience, general information (Frumkina, 2001);

- Spontaneity, because the rapid exchange of replicas and the pace of speech predetermines spontaneity of speech, requires a high level of automatization and readiness to use language material (Harmer, 2012);

- Emotional colouring, as an interlocutor expresses his attitude to the problem under discussion, which is reflected in the intonation, the choice of lexical and grammatical means, in the structure of replicas (Booth, 2012);

- The topic of discussion, where the topic is defined as the content of speech in different spheres of activity (Toptyhina, 2004). At the same time, the topic can acquire both objective and subjective value for communication in a particular situation. Subjectively challenging topics create a motive for starting a discussion between students.

The analysis of the psychological aspects of Training English discussion skills in students of Philology Departments reveals the opportunity of preparing students for self-realization in their professional activities and communication with foreign colleagues.

\subsection{Goal and Objectives}

This research paper intends to determine and analyse the psychological background of Training English discussion skills in students of Philology Departments, substantiate the difficulties of discussion skills training in students of Philology Departments that may arise at the initial stage.

This goal provides the following objectives: to consider the characteristics of discussion, describe age peculiarities of the first-year students, analyse the difficulties of training discussion skills in students of Philology Departments at the initial stage.

\section{Literature Review}

Many scholars, i.e. Brookfield and Preskill (2012), dealt with the problem of psychological aspects in discussion skills training. The researchers identified the structural organization of the discussion, psychological processes and mechanisms involved, psychological features of speaking, and difficulties that arise in the process of communication (Badelina, 2020; Zimniaia, 2001).

To analyse psychological aspects of discussion skills training in students, we describe age peculiarities of the first-year students which have an impact on the learning process and may complicate it.

Consequently, the first-year students are young people aged between 17 and 19 , belonging to a special social category (students). This age group is mentioned as young adults (Bower, 2017a). Developmental psychology provides no single point of view regarding the name of a particular age period: it is called "student age" (17-25 years). It should be mentioned that students are mostly the people who consistently acquire knowledge and improve their professional skills. As a social group, students are characterised by confidence in the future profession, a stable attitude towards the chosen profession, while the level of student perceptions of the profession directly correlates with the level of their attitude towards the studies (Harmer, 2015). So, the more a student knows about the profession, the more positive is his attitude towards the studies. University education has a number of specific features: the teaching and learning style that has changed compared to school. Students experience completely new ways of organization of the educational process because of the changes in both the form of teaching and the form of monitoring their achievements, the number of academic hours of a foreign language etc. All this requires self-organization, development of the ability to distribute their time and power in a busy schedule of university education. 
Young people, especially students, are open to communication: in this period there are new acquaintances maintaining friendly relations. Most scholars determine student age as the age of confusion, self-consciousness, growth, optimism, independence, straightforwardness, criticism and self-criticism, maximalism and decision-making.

That is why discussion skills training aims not only at the development of the language competence in dialogical speech, but also at the harmonious development of the student's personality (Nikolaiev, 2003). Compared to other age groups, students are characterised by the achievement of the highest results in fulfilling verbal-logical tasks, the ability to maintain their intensity for a long time, and switch from one subject to another. The first-year students are more enthusiastic than the graduates, they are already aware of their learning goals. Special studies and practical experience show that failure, individual psychological breakdowns during the first year of studies are not necessarily the result of a student's weak basic knowledge. The reason for the negative learning outcomes, deviations in behaviour may be the inability to control and assess themselves and their actions, the lack of readiness for self-education and responsibility, inefficient time management (Richards \& Rodgers, 2014).

The use of problem learning method activates and develops student's thinking and cognitive processes, autonomy, initiative, unconventional thinking, etc. There are positive changes in the motives for learning. Students begin to evaluate learning activities from the perspective of their future, change the attitude towards the subjects (Wiliam, 2013).

The described psychological and age-specific features allow us to identify the difficulties and obstacles that students usually come across in the process of discussion.

\section{Materials and Methods}

The study of the definition and analysis of the psychological background for the training English discussion skills in students of Philology Departments was prolonged and covered the following interrelated stages.

1. Theoretical analysis, synthesis, and comparison - for conceptualization of philosophical, philological and pedagogical scientific literature, classification and systematization of theoretical and experimental data concerning definition of the concept of discussion, age peculiarities of first-year students, and analysis of difficulty of training discussion skills in students of Philology Departments at the initial stage.

2. Generalization - for the development and interpretation of theoretical sources on the research problem, the results of students' activities, determination of patterns, drawing conclusions.

3. Survey method - determining the motives of students in the process of participating in the discussion and the difficulties that may arise. Survey is a universal method of obtaining information about the subjective world of people, their aspirations, motives, thoughts. The survey method is based on a set of questions offered to the respondent, and the responses make up the necessary information.

The survey was conducted during the academic year of 2018/2019 and involved 681 students. The main objective of the survey was to determine the students' motives in the process of discussion, as well as the obstacles and difficulties that may arise. The survey involved the first-year students learning English as the major at six Ukrainian universities.

The bar chart below (Figure 1) shows the proportion of the Ukrainian university students taking part in the survey. It comprises six universities from different regions of Ukraine: north (Taras Shevchenko Chernihiv National University "Chernihiv Collegium" (ChNU "CC"), 53 students) and southeast region (Bogdan Khmelnitsky Cherkasy National University (ChNU) 37 students), west region (Ternopil Volodymyr Hnatiuk National Pedagogical University (TNPU), 180 students), and the central part of Ukraine (Kyiv National Linguistic University (KNLU), 180 students), Borys Grinchenko Kyiv University (GrKNU) 75 students), Kyiv National University of Trade and Economics (KNUTE) 156 students). 


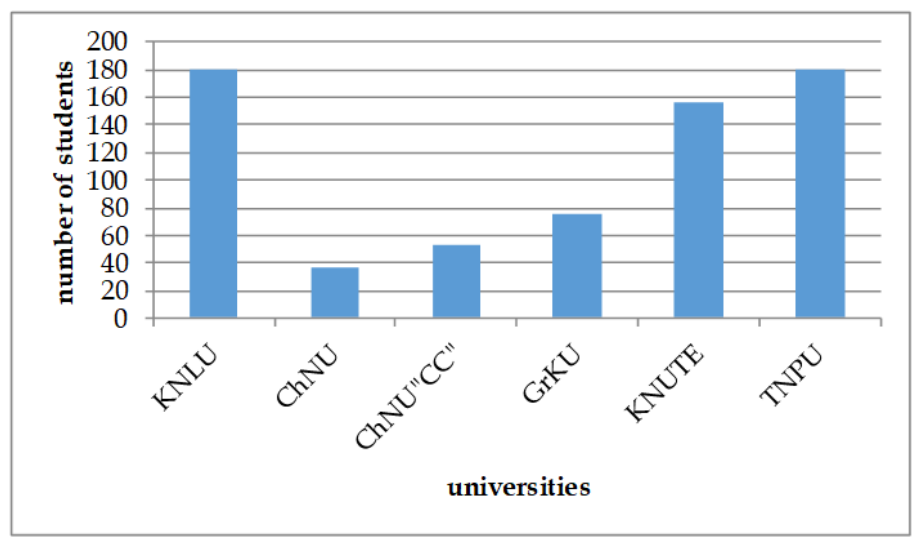

Figure 1. Survey respondents

The total number of the respondents was 681. The figures are higher at the capital universities, as the number of students there is higher compared to other Ukrainian cities. However, the data proves that English is rather popular as a major among Ukrainian students. Most of them expect either to teach it or use it in their future job.

We offered the respondents to fill in a questionnaire. The questionnaire was divided into two parts.

The objective of the first part of the survey was to determine and analyse the motives of students of Philology Departments to participate in the English discussion, as well as their attitude towards training English discussion skills; identify the obstacles and difficulties that arise during the discussion in English.

The objective of the second part of the survey was to identify the attitude of students of Philology Departments towards the problems and issues to be discussed, and identify the most urgent, interesting and challenging problems for the discussion. In order to identify the complexity of the problem, we offered the respondents to indicate the need for additional information to be discussed for each of the problem suggested.

\section{Results}

According to the results of the survey, students ( $70.9 \%$ of respondents) believe that the discussion prepares for spontaneous communication with native speakers and helps to make language learning more interesting $27.3 \%$ of respondents). A high proportion (98.7\%) of respondents is positive about communication, which indicates a high motivation of students to participate in the discussion.

Besides, the results of the survey indicate that a successful discussion requires an interesting and challenging topic, as well as the motivation (30.5\%); ability to express one's personal opinion tactfully, convince interlocutor(s) without imposing one's point of view on others (37.7\%). A quarter $(21.7 \%)$ of the students notice that the ability to listen, understand, and interpret information is necessary for a successful discussion; $10.1 \%$ emphasize the importance of the ability to find a compromise. The interpretation of the above data suggests that students have a high motivation for holding a discussion in English.

However, the majority of respondents find it difficult to participate in discussion in English due to the psychological difficulties: the fear of making mistakes, lack of self-confidence (24.8\%); lack of life experience or knowledge about the subject of discussion (9.4\%). Besides, $14 \%$ of the respondents have some psycholinguistic difficulties: they have difficulties in expressing their opinions, finding arguments; and 7\% of students are passive during the conversation due to the spontaneity of the discussion and lack of time for preparation.

It is also not always easy for students to speak English because of such linguistic difficulties as: the use of lexical units, grammatical structures, phrasal verbs, speech clichés (7.3\%); lack of communication skills and poor vocabulary (34\%), etc. Only 3.4\% of the students of Philology Departments believe they do not have any difficulties in communication.

According to the results of the second part of the survey that involves students' choice of the topics for discussions from the list provided in the questionnaire by the students, all the topics and problems suggested appeared to be relevant for the students of Philology Departments. These are personally, professionally, socially and socio-culturally related issues that can be discussed in class.

Thus, the most urgent problems for students are the following: youth problems (89.7\%): understanding/misunderstanding between parents and children, choice of profession; leisure activities in Ukraine and 
English speaking countries (88.1\%); looking for a job, earning money (86.5\%); studies at university: preparation for classes, exams, daily routines (86.0\%); choice of clothes and shoes depending on the situation (86.4\%); dating, love, early/late marriage, weddings, children upbringing, divorce (85.9\%); personality: character traits, habits (84.9\%).

Students are less concerned about shopping problems or money saving: purchases panning, sales, discounts, etc. (79.3\%); choice of food in different countries, national cuisine (74.6\%); the influence of advertising on the choice of goods (74.5\%); problems related to the environmental protection (74.3\%); eating habits: overweight, diet (73.5\%); seasons and climate: the influence of the seasons on health and the pace of life (71.5); climate in different countries and weather forecast and weather clues (57.5\%); accommodation and accommodation facilities, households (69.1\%).

The problems related to the crime and punishment (53.5\%); reducing crime rates and punishing criminals in different countries (prison, death penalty, etc.) (59.3\%); transport in Ukraine and English speaking countries (54.8), as well as the problems associated with choice of visiting sights in different cities (66.7\%) are the least interesting for students.

However, the respondents determined some of the problems as complex: saving money (81.4\%); the choice of a profession, earning money $(78.1 \%)$; eating habits: overweight, diet $(76.8 \%)$; the influence of advertising on the choice of goods $(76.1 \%)$; the choice of accommodation facilities $(73.8 \%)$; environmental issues $(73.5 \%)$; reducing crime rates and punishing criminals in different countries (66.2\%); choice of a name, its origin and meaning (63.3\%), problems related to the causes of crime $(61.4 \%)$, the formation of personality $(60 \%)$. These figures prove the respondents' willingness to discuss the problems suggested at the English language classes.

Let us consider the students' views on the relevance of the topics for discussion. The topics were taken from the curricula of different Ukrainian universities. We asked to rank them from the most urgent/interesting to the least urgent/interesting (see Figure 2).

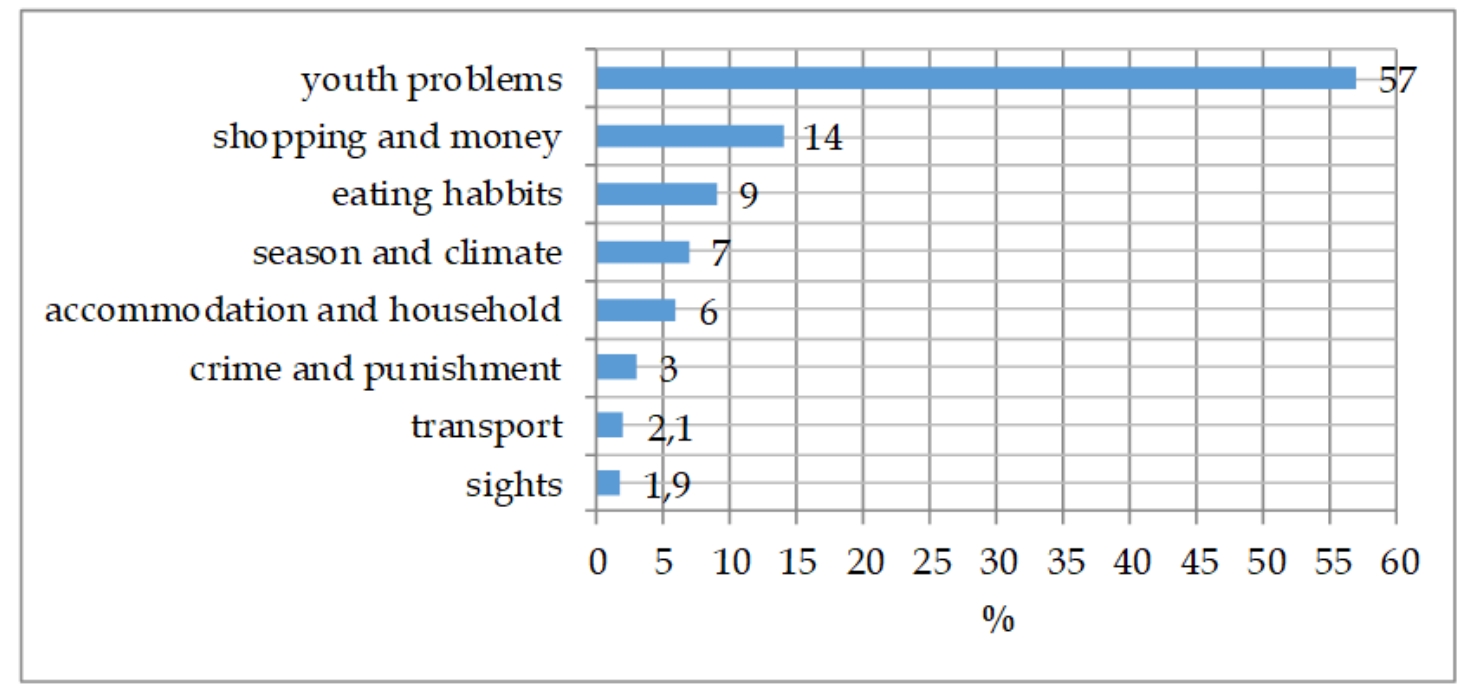

Figure 2. Discussion topics relevance according to the Ukrainian students

Thus, the bar chart shows the relevance of the topics suggested to the Ukrainian students for discussion. It presents the data on the percentage of the students who were asked to rank the suggested topics according to their interests and attitudes.

Overall, the figure shows that a significant number of students who chose 'youth problems' (57\%) as the most urgent among the topics suggested, while figures that concern the others are considered to be less urgent or interesting. 'Shopping and money' ranks second but has only $14 \%$, while the next three: 'eating habits', 'seasons and climate', 'accommodation and household', have similar percentage 9\%, 7\%,6\%, respectively. 'Crime and punishment' 'transport', 'sights', which have from $1.9 \%$ to $3 \%$, are the least urgent/interesting for students.

These findings can be taken into account in further research on the problem of developing curricula, syllabus, teaching materials and manuals for teaching English as the major to the university students.

Summing up, we can conclude that all the figures presented prove the students' high motivation and readiness to communicate and participate in discussions organised by the teachers in class. 


\section{Discussion}

The analysis of the peculiarities of the discussion and the survey allow us to suggest that students may come across certain difficulties during discussion:

1) The difficulties caused by the nature of the dialogical speech (psycholinguistic);

2) Difficulties caused by the language itself (linguistic);

3) Difficulties caused by the students (psychological);

4) Difficulties caused by the way of teaching, teaching methods, manuals and materials (methodological).

Let us consider each of them in more detail.

Psycholinguistic difficulties that arise at the initial stage of learning are due to the following characteristics of the dialogical speech: motivation, contextuality, reversion, emotionality, and spontaneity etc.

Linguistic difficulties include: ellipsis (incomplete replicas), reduction can occur through a 'direct' or 'indirect' ellipse (Averbukh \& Karpova, 2009). A 'direct' ellipse exists in the form of unfinished phrases. For example, the use of the phonetic ellipse, or the reduction in the English language, causes difficulties for students to understand: (you've, I've, he's) and speech patterns such as cause (of course), Twas (it was), What d'you want? (What do you want?) etc. A lexical ellipse is used in abbreviations of phrases such as dorm (dormitory), versity (university), doc (doctor), adv (advertisement), all right (it's all right) etc. The morphological ellipse is the passage of a semantic or auxiliary verb in analytical forms, for example: Have a smoke? (Will you have a smoke?), Done (have done, had done, is done) etc. The syntactic ellipse is due to the following factors: information transfer by non-verbal channels; relying on their replicas or on those that the interlocutor just said; combination of the first and second factors, for example: Look, Jack, how brave a serious! (Mother and son are standing in front of the tiger's cell at the zoo) etc.

The situations that block the cognitive activity and creative self-expression of the students may arise in the process of discussion skills training. We call such situations psychological difficulties, "psychological barriers" or obstacles (in psychology it means a kind of human reaction to the barrier itself). Most often, the reasons that cause psychological difficulties in the process of Training English discussion skills in students are the fear of making a mistake, lack of motivation, irrelevance of the topic of discussion, low self-esteem, the process of adaptation to learning, and anxiety (Bower, 2017b; Hockly, 2018; Renandya, 2014). A lot of students have a fear of making a mistake, although a large number of mistakes are often associated with the formation and development of new speaking skills, while the communication process becomes a strong stress for students who try to meet the expectations of their groupmates, the teacher, and are also afraid of poor scores.

The irrelevance of the discussion topic causes the lack of enthusiasm and motivation for discussion, so, a student's participation in the discussion will be minimal. Controversy motivates students to express their opinions, find arguments and compromise in discussion as they face similar problems in their life, want to know the opinion of their groupmates or express their opinion.

The level of motivation is one of the determining factors for the successful discussion (Bower, 2017b; Renandya, 2014). A high level of motivation can compensate low level of knowledge, while a low level of motivation cannot be compensated by any other component that determines and affects the level of the formation and development of skills. The higher the level of motivation, the more interested is the speaker in the discussion and in its results (Wong, 2020). In the process of learning the motive rarely occurs by itself, it must be created with the help of problem/controversial situations. Besides, such factors as learning environment, including approaches to teaching and student's engagement, are very important (Bower, 2017a). Students' motivation has two groups of active internal motives: cognitive motives (interest in knowledge, the language learning), and conscious motives (responsibility, sense of need, social attitudes, and prestige of future profession). There are common motivation factors, which have substantial impact on students' choice of career: altruism, influence of others, benefits of their future profession, a desire to change a career (Wong, 2020).

The system of teaching changed for the first-year students compared to school: there is adaptation to the loads, methods and forms of work, person's integration to the educational environment, lifestyle and readiness for the conditions of future professional activity (Nabaho, Oonyu \& Aguti, 2017). Students experience expectations, difficulties and disappointments in the process of adaptation to learning (Badelina, 2020). The majority of the first-year students have difficulties in adapting to the learning process. These difficulties include: motivational uncertainty in choice of future profession; lack of moral support from the former school community; lack of skills of rationalization and optimization of individual work (Tarasova, Dukhina, Limonova, Kolesnokova \& Makhova, 2017). 
A large number of students indicated the problems of interpersonal relations in the team (Ketrish et al., 2017). The success of the adaptation of the first-year students is influenced by a number of external and internal factors.

Student's self-esteem reflects satisfaction or dissatisfaction with himself, it creates a basis for perceiving his own success or failure in a certain activity. Low self-esteem is a root cause of different internal conflicts that affect the sphere of communication, both in real conditions and in educational environment. As a result, self-esteem affects a person's speech: the higher the student's self-esteem, the higher is his success in foreign language learning. So, self-esteem results in improvement of students' achievements (Bruzgelevičienè, 2019). It should be considered that a teacherlprofessor also impacts a student's self-esteem. He should not only be pedagogically competent, but master the teaching methods and have the ability to easily explain and attract students' interest. According to the students, the most essential features of a teacher is to be a kind, sensitive, responsible, fair, honest person (Bernard \& Dudek-Różycki, 2020; Romanovskiy, Reznik \& Chebakova, 2019). Student's self-esteem is closely linked to such a psychological barrier as anxiety, which manifests itself in the process of communicating in a foreign language during the lessons. Psychologists distinguish anxiety in general as personal traits, fear of self-expression and inconsistency with the expectations of others and situational anxiety is associated with a particular event or situation, frustration of the need for success. During the discussion, students may experience both types of anxiety. It is associated with a sense of doubt, inconvenience. According to psychological research (Gordieieva, 2004; Zimniaia, 2001), a high level of anxiety, as well as its complete absence can adversely affect the success in learning a foreign language. The most frequent source of anxiety is interacting with native speakers. Evidence for two types of anxious language learner emerged: retrieval interference and skills deficit (Woodrow, 2006). Foreign language anxiety can occur if students are exposed to several negative experiences in a foreign language context. Moreover, students lose faith in their abilities, escape from taking part in in-class activities.

The foreign language anxiety components are as follows:

1. Communication apprehension, which arises from learners' inability to adequately express mature thoughts and ideas.

2. Fear of negative social evaluation, which arises from a learner's need to make a positive social impression on others.

3. Test anxiety, an apprehension about academic evaluation (Elaldi, 2016).

Having analysed the psycholinguistic, linguistic and psychological difficulties that students of Philology Departments may encounter while holding English discussion, let us consider methodological difficulties. Methodological difficulties are manifested in the discrepancy between the existing system of students' knowledge and new phenomena, facts, the level of communication skills, lack of life experience or knowledge of the subject matter, problem, etc. The way of teaching, teaching methods, materials and manuals should be also taken into account. Besides, most students are not able to discuss problems without special preparation and additional information about the problem, which should be provided before the discussion starts. The survey proved the lack of such materials and an urgent need in developing them.

\section{Conclusion}

Thus, the considered current situation in Ukraine, background and aspects of training discussion skills in students of Philology Departments prove a high motivation and readiness of Ukrainian students to take part in discussions organised by the teachers in class in order to discuss the problems that are urgent and interesting to them. This, in order, arises the problem of developing special teaching methods on discussion skills training in students of Philology Departments, and, in particular, elaborating new teaching materials and manuals to meet students' interests and problem learning principles, while taking into consideration students' preferences and the above-mentioned difficulties they may come across. This can be the prospects for further research in this field.

\section{Research Limitations}

We didn't study the psychological peculiarities of the second-, third- and fourth-year students in our research. They do not differ much if it concerns the second-year students, the psychological peculiarities and interests of the fourth-year students are different. The students of this age are more concerned about their future profession and, as a result, about discussing professionally oriented issues. It leads to the need to organise debates for discussing issues that concern their future profession, in particular with master's degree students. All this requires additional investigation and was not the goal of the study, which dealt with the problem of psycholinguistic background of discussion skills training in students of Philology Departments at the initial stage of learning English as a foreign language. 


\section{Recommendations for Further Research}

In further research, we recommend to expand understanding of the aspects that constitute the limitations in this study. It is important to study psychological peculiarities and interests of the undergraduates and graduates, as well as post-graduate students. The results of the study should lay the foundation for the development of curricula and syllabus, and their taking into consideration while creating new teaching materials and manuals.

The further research should also concern the peculiarities of organising discussion especially if it aims at discussing professionally oriented issues. In such a case, the discussion may turn into debates that have a different structure and features. Specific features of discussion considered in our other publications can be taken into account.

One more thing to be studied is the problem of preparation the university English teachers for Training English discussion skills in their students. There is a need to develop specific tools and methodology to make them able to organise such types of activities that involve real life communication in class.

There is also a need to study the similar problem and current state not only in Ukraine (the country of this research) but in other European countries as well. It will help to compare the needs and interests of the students, and it gives the opportunity to decide whether the results of the conducted research are relevant not only for Ukraine but for other European countries as well. As a result, this will allow implementing the other achievements into the process of Training English discussion skills in students of Philology Departments by university teachers in other countries.

\section{References}

Averbukh, K. Y., \& Karpova, O. M. (2009). Lexical and phraseological aspects of translation. Moscow, Russia: Akademia.

Badelina, M. V. (2020). Process of adaptation of first-year students to study at university as pedagogical phenomenon: structure and characteristics. Amazonia Investiga, 9(27), 460-477. https://doi: 10.34069/AI/2020.27.03.50

Bernard, P., \& Dudek-Różycki, K. (2020). The impact of professional development in inquiry-based methods on science teacher' classroom practice. Journal of Baltic Science Education, 19(2), 201-219. https://doi: $10.33225 / \mathrm{jbse} / 20.19 .201$

Booth, D. (2013). I've got something to say: How student voices inform our teaching. Markham, Canada: Pembroke Publishers Limited.

Bower, K. (2017a). Explaining motivation in language learning: a framework for evaluation and research. The Language Learning Journal, 47(5), 558-574. https://doi.org/10.1080/09571736.2017.1321035

Bower, K. (2017b). Speaking French alive: learner perspectives on their motivation in content and language integrated learning in England. Innovation in Language Learning and Teaching, 13(1), 45-60. https://doi.org/10.1080/17501229.2017.1314483

Brookfield, S. D., \& Preskill, S. (2012). Discussion as a way of teaching: Tools and techniques for democratic classrooms. $2^{\text {nd }}$ ed. New York, NY: John Wiley \& Sons.

Bruzgelevičienè, R. (2019). Intensive consulting for schools by mitigating the impact of social, economic and cultural context on students' learning achievements. Pedagogika, 136(4), 17-41. https://doi.org/10.15823/p.2019.136.2

Chernysh, V. V. (2013). Methods of the development of professionally oriented English-speaking competence in future teachers. Kyiv, Ukraine: Lenvit.

Elaldi, S. (2016). Foreign language anxiety of students studying English language and literature: A sample from Turkey. Educational Research and Reviews, 11(6), 219-228. https://doi: 10.5897/ERR2015.2507

Frumkina, R. M. (2001). Psycholinguistics. Moscow, Russia: Akademia.

Gordieieva, A. Y. (2004). Teaching senior pupils to discuss problems in English in the process of intercultural communication (Master's thesis). Kyiv National Linguistic University, Kyiv, Ukraine.

Harmer, J. (2012). Essential teacher knowledge. Harlow, UK: Pearson Education Limited.

Harmer, J. (2015). The practice of English language teaching. $5^{\text {th }}$ ed. London, UK: Pearson Education Limited.

Hockly, N. (2018). Blended learning. ELT Journal, 72(1), 97-101. https://doi.org/10.1093/elt/ccx058

Ketrish, E. V., Andryukhina, T. V., Tret'yakova, N. V., Permyakov, O. M., Barakovskikh, K. N., \& Safronovich, I. E. 
(2017). On the problem of first-year students' adaptation to the learning process in a university. Journal of Fundamental and Applied Sciences, 9(7S), 1016-1031. http://dx.doi.org/10.4314/jfas.v9i7s.92

Lawtie, F. (2016). Teaching speaking skills 2-overcoming classroom problems. New York, NY: Palgrave Macmillan.

Nabaho, L., Oonyu, J., \& Aguti, J. N. (2017). Good teaching: Aligning student and administrator perceptions and expectations. Higher Learning Research Communications, 7(1), 1-16. https://doi:10.18870/hlrc.v7i1.321

Nikolaiev, S. Y. (Ed.). (2003). Pan-European recommendations for language education: learning, teaching, evaluation. Kyiv, Ukraine: Lenvit.

Renandya, W. A. (2014). Motivation in the language classroom. Alexandria, VA: TESOL International Association.

Richards, J. C., \& Rodgers, T. S. (2014). Approaches and methods in language teaching. Cambridge, UK: Cambridge University Press.

Romanovskiy, O., Reznik, S., \& Chebakova, Y. (2019). Teacher leader at technical university. Advanced Education, 13, 63-69. https://doi.org/10.20535/2410-8286.148316

Tarasova, S., Dukhina, T., Limonova, O., Kolesnokova, T., \& Makhova, I. (2017). Socio-psychological adaptation of first year university students. Revista Espacios, 38(56), 35-41.

Thornbury, S. (2009). How to teach speaking. Harlow, UK: Pearson Education Limited.

Toptyhina, N. M. (2004). Teaching discussion on the material of literary texts in the process of learning English as a second foreign language (Master's thesis). Kyiv National Linguistic University, Kyiv, Ukraine.

Wiliam, D. (2013). Assessment: The bridge between teaching and learning. Voices from the Middle, 21(2), 15-20.

Wong, R. (2020). Becoming an EFL teacher: A re-investigation of student teachers' motivation. English Language Teaching, 13(5), 64-79. https://doi: 10.5539/elt.v13n5p64

Woodrow, L. (2006). Anxiety and speaking English as a second language. RELC journal, 37(3), 308-328. https://doi.org/10.1177/0033688206071315

Zimniaia, I. A. (2001). Pedagogical psychology. $2^{\text {nd }}$ edition. Moscow, Russia: Logos. 